EXPERIMENTAL STUDY

\title{
Fas and Fas ligand gene expression in autoimmune thyroiditis in $\mathrm{BB} / \mathrm{W}$ rats
}

\author{
M Blüher, K Krohn, H Wallaschofski, L E Braverman ${ }^{1}$ and R Paschke \\ III Medical Department, Faculty of Medicine, University of Leipzig, Germany and ${ }^{1}$ Genetics Division, Brigham and Women's Hospital, Boston, \\ Massachusetts, USA
}

(Correspondence should be addressed to R Paschke, University of Leipzig, III Medical Department, Philipp-Rosenthal-Straße 27, D-04103 Leipzig, Germany; Email: pasr@medizin.uni-leipzig.de)

\begin{abstract}
Objective: Apoptosis via the Fas pathway is a potential mechanism for thyroid tissue destruction leading to clinical hypothyroidism in Hashimoto's thyroiditis (HT). Recent studies reported contradictory results regarding the regulation of Fas/Fas ligand (FasL) expression by cytokines in vitro. We therefore determined the Fas and FasL gene expression in the BioBreeding/Worcester (BB/W) rat thyroiditis model, which can be regarded as a model for HT.

Methods: In order to obtain $\mathrm{BB} / \mathrm{W}$ rats with spontaneous, iodine-induced or without lymphocytic thyroiditis (LT), rats were divided into 3 groups: 55-day-old rats after 24 days of iodine administration, 75-day-old rats after 45 days of iodine administration, and 101-day-old rats respectively. The gene expression of Fas, FasL, and interleukin (IL)- $1 \beta$ was determined by Genescan fragment analysis using reverse polymerase chain reaction. Serum thyroglobulin (TG) antibody concentrations were measured and the extent of lymphocytic infiltration of one thyroid lobe was histologically graded.

Results: Fas and FasL gene expression was significantly higher in rats with LT and correlated with the extent of lymphocytic infiltration and the TG antibody level. There was no evidence that the expression of IL-1 $\beta$ or other cytokines is related to the expression of Fas or its ligand.

Conclusions: The increased expression of Fas and FasL in LT of $\mathrm{BB} / \mathrm{W}$ rats suggests the involvement of the Fas pathway in the pathogenesis of $\mathrm{LT}$ in $\mathrm{BB} / \mathrm{W}$ rats. However, in contrast to results of recent in vitro studies, in the $\mathrm{BB} / \mathrm{W}$ rat Fas/FasL expression is not regulated by IL-2, $-4,-6,-10,-12$, interferon $\gamma$, and tumor necrosis factor $\alpha$.
\end{abstract}

European Journal of Endocrinology 141 506-511

\section{Introduction}

The spectrum of human autoimmune thyroid disease ranges from Graves' disease (GD) to Hashimoto's thyroiditis (HT). HT is characterized primarily by destruction of thyroid tissue. Immunohistological investigation of HT tissue indicates that apoptosis might be a possible mechanism for cell death of thyrocytes $(1,2)$, whereas reduced thyrocyte cell death was observed in the stimulated thyroids from GD patients (2).

It has been suggested that activation of Fas antigen on thyrocytes by binding of the Fas ligand (FasL), which is present on lymphocytes, is a potential mechanism by which thyroid cells undergo apoptosis (3-5). Changes in the level of Fas or FasL gene expression could be one of the regulating factors of the Fas pathway (6-8). In recent studies, cytokines have been demonstrated to induce expression of Fas in vitro. Giordano et al. (4) reported that interleukin (IL)- $1 \beta$-induced Fas expression results in apoptosis via expression of FasL on thyrocytes.
Moreover, Kawakami et al. (9) reported that Fas gene expression only led to apoptosis when thyrocytes were exposed to interferon $\gamma$ (IFN $\gamma$ ). Other in vivo studies in human thyroid tissue $(10,11)$ and $\beta$-cells of non-obese diabetic (NOD) mice (12) also support the suggestion that induction of Fas expression is induced in vitro by cytokines. In contrast, Arscott et al. (3) reported that pretreatment of thyrocytes with IFN $\gamma$ did not substantially alter the amount of Fas mRNA compared with untreated cells in vitro. Furthermore, Rasmussen et al. (13) demonstrated that IL-1 $\beta$ does not induce apoptosis in human thyrocytes in vitro. Differences in culture conditions and different sources of thyroid tissue, i.e. from patients with nontoxic goiter versus HT (4) and GD and surrounding tissue from follicular and papillary carcinomas and multinodular goiter (3), are possible explanations for these contradictory results.

Therefore, conclusions regarding the induction of Fas/FasL by cytokines in vivo cannot be drawn. In order to evaluate the in vivo relevance of Fas expression in 
different stages of autoimmune thyroiditis, we investigated the expression of Fas and its ligand in the BioBreeding/Worcester $(\mathrm{BB} / \mathrm{W})$ rat thyroiditis model. We have previously reported that the thyroiditis of $\mathrm{BB} / \mathrm{W}$ rat is characterized by an expression of type 1 T-helper cell (Th1)-related cytokines (14).

\section{Materials and methods}

\section{Animals}

$\mathrm{BB} / \mathrm{W}$ rats were obtained from the University of Massachusetts breeding colony and were treated and killed as follows to compare cytokine gene expression in rats with and without lymphocytic thyroiditis (LT) at 2 different ages. Group I: 55 -day-old animals $(n=15)$ were treated for 24 days with $0.05 \%$ iodide water $(0.64 \mathrm{~g}$ $\mathrm{NaI} / \mathrm{l}$ ). Since these young animals do not develop thyroiditis, this group was used to control for specific effects of the iodine treatment used in group II. Group II: 75-day-old animals, all after 45 days of iodine treatment $(0.64 \mathrm{~g} \mathrm{NaI} / \mathrm{l})$, subdivided according to thyroid histology into group $\mathrm{II}_{\text {pos }}, n=19$, with thyroiditis and group $\mathrm{II}_{\mathrm{neg}}, n=12$, without thyroiditis. Group III: 101day-old animals, all with no iodine treatment, subdivided according to thyroid histology into group $\mathrm{III}_{\text {pos }}$, $n=14$, with spontaneous thyroiditis and group $\mathrm{III}_{\text {neg, }}$, $n=20$, without thyroiditis.

At the time of death, tissue samples were obtained from the thyroid, spleen, and liver and immediately frozen in liquid nitrogen.

\section{Histological grading of thyroid biopsies}

One thyroid lobe from each thyroid was embedded in paraffin. Paraffin sections $(4 \mu \mathrm{m})$ were stained with hematoxylin and eosin and histologically graded by a pathologist according to the relative extent of thyroid tissue infiltrated with lymphocytes and macrophages using the following scale: 0 , normal thyroid; $>0$, no lymphocytic thyroiditis, increased prevalence of chronic inflammatory cells; $0.5-1$, lymphocytic infiltration less than $10 \%$; $1-2$, lymphocytic infiltration $10 \%$ to $30 \%$; 3 , lymphocytic infiltration $31 \%$ to $50 \%$; 4 , lymphocytic infiltration greater than $50 \%$.

\section{Assay for anti-thyroglobulin (TG) antibodies}

Blood samples were obtained from the animals at the time of death by left ventricular exsanguination. Several serum aliquots from each rat, stored at $-65^{\circ} \mathrm{C}$, were assayed in the same assay for TG antibody. Serum antiTG was measured in triplicate by an enzyme-linked immunosorbent assay according to the method of Rennie et al. (15). The results were expressed as optical density (OD). Studies on 103 control rats revealed a mean OD of $0.035 \pm 0.007$ (mean \pm S.D.) (15).

\section{RNA extraction and CDNA synthesis}

Total RNA was isolated from thyroid, liver, and spleen by a single step method using TRIzol Reagent (Gibco BRL, USA) according to the manufacturer's protocol. Gel electrophoresis on $2 \%$ agarose gels was used as RNA quality control.

cDNA was prepared with oligo-dT primers and murine myelomonocytic lymphoma virus (MMLV) reverse transcriptase (Bethesda Research Laboratories, Gaithersburg, MD, USA). Total RNA (0.5-1 $\mu \mathrm{g})$ and oligo-dT primers $(1 \mu \mathrm{g})$ in $20 \mu \mathrm{l} \mathrm{H}_{2} \mathrm{O}$ were heated to $65^{\circ} \mathrm{C}$ for $10 \mathrm{~min}$ and then incubated for $1 \mathrm{~h}$ at $37^{\circ} \mathrm{C}$ after adding $10 \mu \mathrm{l}$ of a mixture containing $6 \mu \mathrm{l} 5 \times$ concentrated reverse transcription buffer, $2 \mu \mathrm{l}$ $0.1 \mathrm{mmol} / \mathrm{l}$ dithiothreitol, $1 \mu \mathrm{l} 10 \mathrm{mmol} / \mathrm{l} \mathrm{dNTP}$, and $1 \mu \mathrm{l}$ MMLV reverse transcriptase $(200 \mathrm{U} / \mu \mathrm{l})$. The samples were then heated for $5 \mathrm{~min}$ at $95^{\circ} \mathrm{C}$.

Because of the small amount of thyroid tissue, reverse transcription-polymerase chain reaction (RT-PCR) was used as a sensitive method for cytokine mRNA analysis. To correct for variations in the quality of RNA extraction, the amplification of the ribosomal protein S-6 was used, as it is known to be equally transcribed in different cells. We did not perform multiplex PCRs. PCR was carried out in a total volume of $50 \mu \mathrm{l}$ containing PCR buffer (10× OPTIPERFORM buffer III (InVitek $\mathrm{GmbH}$, Berlin, Germany):500 mmol/l KOH pH 9.2 at $25^{\circ} \mathrm{C} ; 160 \mathrm{mmol} / \mathrm{l} \quad\left(\mathrm{NH}_{4}\right)_{2} \mathrm{SO}_{4} ; 0.1 \%$ Tween 20; $2 \mathrm{mmol} / \mathrm{l} \mathrm{MgCl}_{2}$ ), $5 \mu \mathrm{l}$ cDNA with $1 \mathrm{U}$ CombiPool DNA Polymerase Mix (InVitek $\mathrm{GmbH}$ ) in vitro, $0.5 \mathrm{mmol} / \mathrm{l}$ dNTPs and $1 \mu \mathrm{mol} / \mathrm{l}$ sense and antisense primers. Primers were all based on rat sequences and were chosen to span introns. Extra bands suggesting interference by genomic DNA were not seen; contamination was excluded by water controls. Amplifications were carried out using cycles ( 32 for Fas, 36 for FasL) of $94{ }^{\circ} \mathrm{C}$ for $30 \mathrm{~s}, 56^{\circ} \mathrm{C}$ (Fas, FasL) for $30 \mathrm{~s}$, and $72{ }^{\circ} \mathrm{C}$ for $30 \mathrm{~s}$. The primer sequences were as follows: Fas: sense $5^{\prime} \mathrm{AAC}$ ATG AGA ACA TCC TGT GCC 3', antisense $5^{\prime}$ TCC CTG CTC ATG ATG TCT ACC 3'; FasL: sense 5' TTC TTT ATC ATG GAT GCC AGG 3', antisense 5' GAA CAG TCT TCT TCC CAT CTG G 3'. PCR product quantification for Fas, FasL and all cytokines was performed in the log-linear phase of the amplification. RNA was quantified using OD readings at $260 / 280 \mathrm{~nm}$. To correct for variations in RNA quality, the ribosomal protein S-6 cDNA was amplified. To control for variations in the reverse transcription reaction, total RNA was mixed with an in vitro transcribed RNA. The in vitro transcript from a 70 bp deletion variant of the endogenous IL- 6 transcript was prepared from plasmid DNA. The in vitro RNA was added in a constant dilution of 1:10000 (3 $\mu \mathrm{l})$ to each reverse transcriptase reaction.

\section{Fragment analysis and statistics}

PCR product quantification was performed with the ABI 373A DNA Sequencer System using Genescan software 
(PE Applied Biosystems, Foster City, CA, USA). Fragment analysis data for each cytokine and animal were normalized for the fragment intensity of S-6 to correct for variations in RNA quality and to the internal standard to control for variations in the reverse transcription reaction. Due to the inappropriate RNA quality, two samples with S-6 results 2 standard deviations below the mean of all animals were excluded from further statistical analysis. The data were expressed as means \pm S.E.M. Data were compared with ANOVA; a $P$ value of less than 0.05 was regarded as significant. Correlations between variables were tested with Spearman's correlation test, obtaining the correlation coefficient (r). A $P$ value less than 0.05 was accepted as significant. To correct the statistical analysis for the multiple tests performed, Bonferroni's $\alpha$-adjustment was carried out, getting a new significance level of 0.008 .

\section{Results}

\section{Fas/FasL expression in the spleen}

Spleen tissue was used to establish the conditions for PCR amplification. The conditions were sufficiently sensitive to detect Fas and FasL gene expression in all splenic tissue samples. There were no significant differences in either Fas or FasL expression between the groups. The mean Fas/ FasL fragment intensities $( \pm$ S.D.) in the spleen were: Fas, $8960 \pm 3154$ and FasL, 10469 \pm 4398 . No correlation between the previously reported $\mathrm{IL}-2,-4,-6,-10$, tumor necrosis factor- $\alpha$ (TNF $\alpha)$, and IFN $\gamma$ gene expression and Fas/FasL gene expression in the spleen was observed, i.e. rats with detectable expression of these cytokines had no significant differences for Fas and FasL normalized fragment intensity (Fas: 9210 \pm 3529 , FasL: 11014 \pm 4964$)$ compared with rats without IL-2, -4, -6, $-10, \mathrm{TNF} \alpha$, and IFN $\gamma$ gene expression in the spleen (Fas: $8537 \pm 2864$, FasL: $9840 \pm 4005)$. IL-1 $\beta$ gene expression was detected in 10 spleens without correlation to either Fas $(r=-0.054, P=0.84)$ or FasL $(r=0.087, P=0.45)$ fragment intensity.

\section{Fas/FasL gene expression in the thyroid}

Fas expression was detectable in all rat thyroids $(n=80)$, with significant differences between the groups (Fig. 1). The incidence of detected FasL gene expression (Fig. 2) and the FasL fragment intensity (Fig. 3) in the rat thyroid were significantly different between the groups. The FasL fragment intensity correlated with the fragment intensity of Fas $(r=0.794, P=0.001)$. The highest normalized fragment intensity was detected in the thyroids of rats with $\mathrm{LT}$ (group $\mathrm{II}_{\text {pos }}$ : Fas: 76503 \pm 22945 ; FasL: 51978 \pm 15300 ; group $\mathrm{III}_{\text {pos: }}$ : Fas: 50039 \pm 14397 ; FasL: 31810 \pm 9576$)$. Fas/FasL fragment intensity in the thyroids of rats without LT

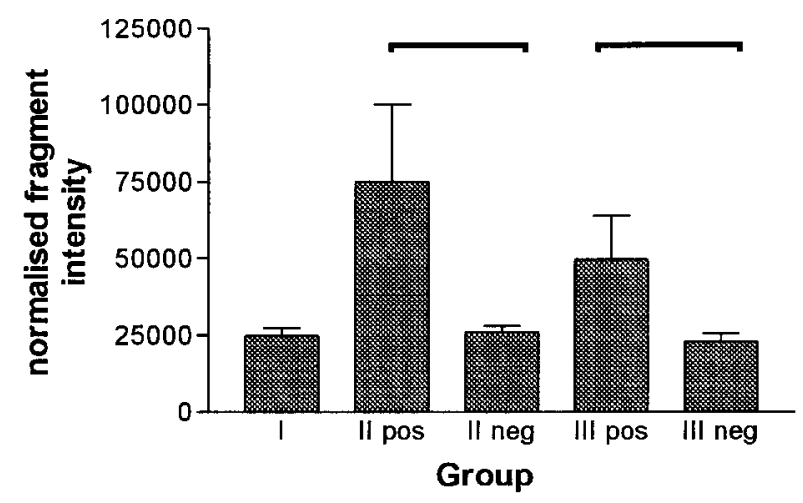

Figure 1 Fas gene expression in the thyroids of BB/W rats. Fas fragment intensity (mean \pm S.E.M.) was determined with Genescan analysis, normalized for S-6 and internal standard. Brackets indicate significant differences $(P<0.05)$ between age- and treatment protocol-matched groups.

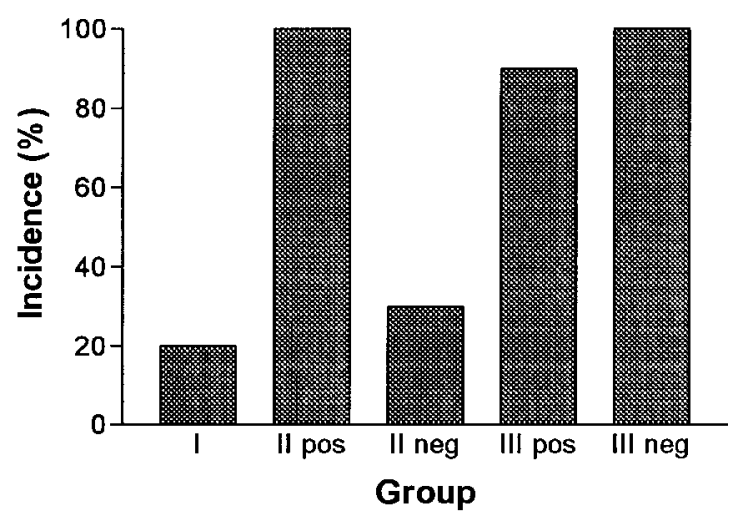

Figure 2 Frequency (percentage incidence) of BB/W rats with detectable FasL gene expression in the different groups.

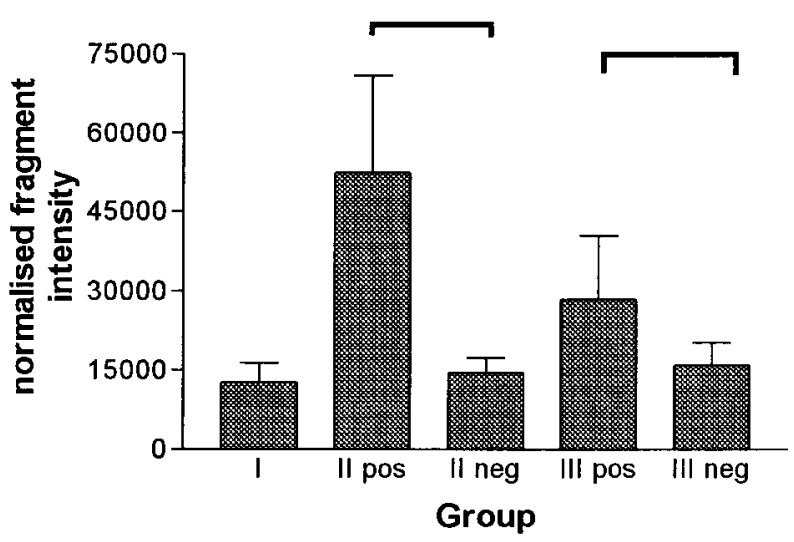

Figure 3 FasL gene expression in the thyroids of BB/W rats. FasL fragment intensity (mean \pm S.E.M.) was determined with Genescan analysis, normalized for S-6 and internal standard. Brackets indicate significant differences $(P<0.05)$ between age- and treatment protocol-matched groups. 
Table 1 Correlation ( $r$ ) of normalized Fas/FasL cDNA fragment intensity with normalized fragment intensity of IL-1 $\beta$ and other previously determined cytokines. Level of significance $(\boldsymbol{P}$ value $)$ is in parentheses.

\begin{tabular}{|c|c|c|}
\hline Cytokines & $\begin{array}{l}\text { Correlation coefficients } \\
\text { with Fas fragment intensity }\end{array}$ & $\begin{array}{l}\text { Correlation coefficients } \\
\text { with FasL fragment intensity }\end{array}$ \\
\hline IL-1 $\beta$ & $-0.096(0.29)$ & $0.154(0.083)$ \\
\hline IL-6 & $-0.034(0.9)$ & $0.109(0.18)$ \\
\hline IL-2 & $0.15 \quad(0.07)$ & $0.29(0.2)$ \\
\hline IL-12p40 & $0.522(0.09)$ & $0.39 \quad(0.4)$ \\
\hline $\mathrm{IFN} \gamma$ & $0.429(0.34)$ & $0.508(0.08)$ \\
\hline $\operatorname{TNF} \alpha$ & $0.28 \quad(0.28)$ & $0.36 \quad(0.31)$ \\
\hline
\end{tabular}

(group $\mathrm{I}_{\text {, }} \mathrm{II}_{\text {neg }}$, $\mathrm{III}_{\text {neg }}$ ) was significantly lower than in the thyroids of rats with LT $(P<0.05)$.

The normalized fragment intensity of Fas $(r=0.578$, $P<0.008)$ and of FasL $(r=0.680, P<0.008)$ correlated with the extent of lymphocytic infiltration of the thyroid tissue. Moreover, TG antibody concentration also correlated with the normalized fragment intensity of Fas $(r=0.508, P<0.008)$ and its ligand $(r=0.589, P<0.008)$.

There was no correlation between the expression of the previously determined cytokines (14) and the expression of Fas or FasL (Table 1). Fas and FasL correlated with the relative extent of thyroid tissue infiltrated with lymphocytes. No correlation could be found between the previously determined TNF $\alpha$ (14) and Fas or FasL fragment intensity.

IL-1 $\beta$ gene expression was detected in all thyroid tissue samples, without significant differences in fragment intensity between the groups (Fig. 4). There was no correlation between the IL-1 $\beta$ fragment intensity and the fragment intensity of Fas $(r=-0.096, P=0.29)$ or FasL $(r=0.154, P=0.083)$.

\section{Discussion}

Apoptotic cell death is abnormally accelerated during the tissue destruction induced by lymphocytic

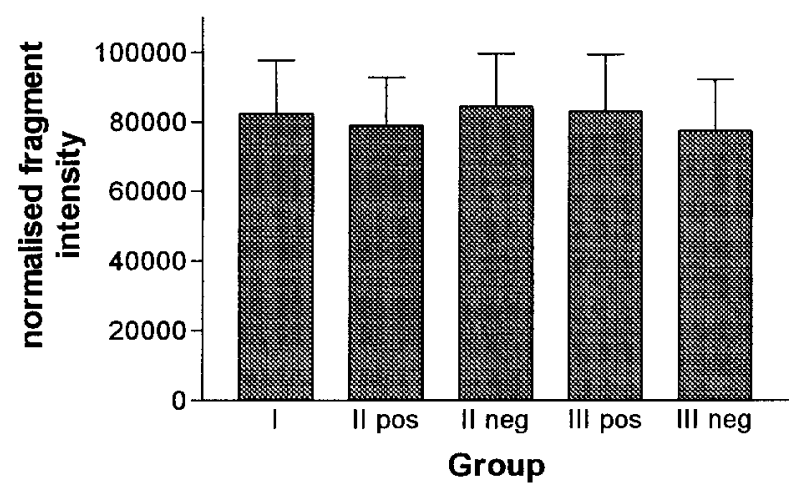

Figure $4 \mathrm{IL}-1 \beta$ gene expression in the thyroids of BB/W rats. IL- $1 \beta$ fragment intensity (mean \pm S.E.M.) was determined with Genescan analysis, normalized for S-6 and internal standard. The differences between the groups were not significant $(P>0.05)$. infiltration of thyroid tissue from patients with Hashimoto's thyroiditis (1). However, whether Fas is constitutively expressed on thyrocytes and whether Fas gene expression is regulated by inflammatory cytokines is controversial $(3,4,9)$. In the present study, Fas gene expression was detected in all thyroid tissue samples. This result supports the findings of Kawakami et al. (9) and Arscott et al. (3), who demonstrated constitutive Fas gene expression on thyrocytes. Fas gene expression was significantly higher in rat thyroids with LT. The correlation between the Fas fragment intensity and the amount of lymphocytic infiltration in the thyroid suggests that infiltrating lymphocytes are the main source of increased Fas expression. The observation that the previously reported TG antibody levels (14) correlate with the expression of Fas and FasL suggests a relationship between the activity of the autoimmune process and the expression of genes related to apoptosis.

The major aim of the present study was to determine whether a specific cytokine pattern influences Fas and FasL gene expression in an animal model. Recent in vitro studies with different methods of Fas detection suggest that cells must be exposed to cytokines $(10,11)$, such as IL-1 $\beta$ (12), $\operatorname{IFN} \gamma(16,17)$ or $\operatorname{TNF} \alpha(16,18,19)$, to express Fas. These results are supported by previous in vitro studies with thyrocytes $(4,9)$. In contrast, Arscott et al. (3) reported that pretreatment of thyrocytes with IFN $\gamma$ did not substantially alter the amount of Fas mRNA compared with untreated cells in vitro and Rasmussen et al. (13) demonstrated that IL-1 $\beta$ does not induce apoptosis in human thyrocytes in vitro.

In the present study there was no correlation between IL-1 $\beta$ gene expression or the previously described IL-2, $-4,-6,-10,-12 \mathrm{p} 40, \mathrm{IFN} \gamma$, and $\mathrm{TNF} \alpha$ gene expression (14) and Fas or FasL gene expression. These results contrast with the findings of Giordano et al. (4) and Kawakami et al. (9), who demonstrated increased Fas expression after incubation of thyrocytes with IL- $1 \beta$ or IFN $\gamma$. Our results also do not support the recent observation that Fas expression in $\beta$-cells of NOD mice islets correlates with the expression of proinflammatory cytokines (18) thus leading to apoptosis. In agreement with our findings, Rasmussen et al. (13) found that incubation of thyroid cells with $\mathrm{IL}-1 \beta$ did not induce 
apoptosis in thyrocytes in vitro. The most likely explanation for these different results is that thyrocyte cell cultures do not reflect the conditions and cell milieu in vivo.

There was a discrepancy between the incidence of positive FasL in rat thyroids and the differences in the fragment intensity between the groups. Thus, young rats without LT (group I and $\mathrm{II}_{\text {neg }}$ ) had an incidence of detectable FasL below 33\%, whereas FasL was detected in all 101-day-old rats without LT rats (group III $_{\text {neg }}$ ).

Since there is evidence that FasL is constitutively expressed on purified normal thyrocytes (4), the higher incidence of detected FasL in older rats without LT compared with younger rats without LT might reflect the increased FasL gene expression in thyrocytes. Whether this is due to the age of these $\mathrm{BB} / \mathrm{W}$ rats has to be clarified. The fragment intensity of FasL in rats with detectable FasL gene expression correlated with the fragment intensity of Fas. This is in agreement with studies of human hepatocellular carcinoma (20) and chronic hepatitis B infection (21) and the parallel increase in Fas and FasL in rats with LT could reflect increased apoptotic tissue destruction. The PCR technique does not allow the specific cell responsible for the Fas and FasL gene expression to be identified and we did not investigate characteristic morphological changes of apoptosis in the thyroids of $\mathrm{BB} / \mathrm{W}$ rats. Moreover, it is known that molecules like $\mathrm{Bcl}-2$ suppress the Fas pathway (22) and Arscott et al. (3) reported that Fasmediated apoptosis in thyroid cells is regulated by a labile protein inhibitor. However, Tamura et al. (23) recently showed that increased Fas expression in the thyroid paralleled the presence of apoptosis determined by electron microscopy and terminal desoxy-UTP nick end labelling (TUNEL). Therefore, it is most likely that Fas gene expression correlates with its apoptotic function.

To identify tissue-specific differences in Fas gene expression in $\mathrm{BB} / \mathrm{W}$ rats and to control for a generalized up-regulation of Fas gene expression, the Fas fragment intensity in thyroid tissue was compared with the Fas expression in the spleens of all rats. Fas gene expression was detected in the spleens of all $\mathrm{BB} / \mathrm{W}$ rats. These results are in accordance with the constitutive Fas and FasL expression described in spleens of mice (24). Rats without LT did not have significantly different Fas fragment intensity in the thyroid compared with that in the spleen, whereas rats with LT had significantly higher Fas fragment intensity in the thyroid compared with the spleen. This result could be due either to the increased number of lymphocytes in the thyroids of rats with LT or to an up-regulation of Fas expression on thyrocytes. Further studies are necessary to clarify which cell type is producing the Fas and FasL mRNA, since this was not possible in our experimental design.

In conclusion, we observed that $\mathrm{LT}$ in $\mathrm{BB} / \mathrm{W}$ rats is characterized by increased expression of Fas and its ligand positively correlating with the intensity of lymphocytic infiltration and the level of TG antibodies. In contrast to previous in vitro findings, there was no evidence that cytokine gene expression correlates with the expression of Fas and FasL.

\section{Acknowledgements}

This work was supported by Wilhelm Sander Stiftung and in part by DK 18919, NIH, Bethesda, MD, USA.

\section{References}

1 Kotani T, Aratake Y, Hirai K, Fukazawa Y, Sata H \& Ohtaki S. Apoptosis in thyroid tissue from patients with Hashimoto's thyroiditis. Autoimmunity 199520 231-236.

2 Tanimoto C, Hirakawa S, Kawasaki H, Hayakawa N \& Ota Z. Apoptosis in thyroid diseases: a histochemical study. Endocrine Journal 199542 193-201.

3 Arscott PL, Knapp J, Rymaszewski M, Bartron JL, Bretz JD, Thompson NW et al. Fas (APO-1,CD 95)-mediated apoptosis in thyroid cells is regulated by a labile protein inhibitor. Endocrinology 1997138 5019-5027.

4 Giordano C, Stassi C, De Maria R, Todaro M, Richiusa P, Papoff G et al. Potential involvement of Fas and its ligand in the pathogenesis of Hashimoto's thyroiditis. Science 1997275 960-963.

5 Mitsiades N, Poulaki V, Kotoula V, Mastorakos, G, TseleniBalafouta S, Koutras DA et al. Fas/Fas ligand up-regulation and bcl-2 down-regulation may be significant in the pathogenesis of Hashimoto's thyroiditis. Journal of Clinical Endocrinology and Metabolism 199883 2199-2203.

6 Nagata S \& Goldstein P. The Fas death factor. Science 1995267 1449-1456.

7 Owen-Schaub LB, Yonehara S, Crump WL \& Grimm EA. DNA fragmentation and cell death is selectively triggered in activated human lymphocytes by Fas antigen engagement. Cellular Immunology 1992140 197-205.

8 Suda T, Takahashi T, Goldstein P \& Nagata S. Molecular cloning expression of the Fas ligand, a novel member of the tumor necrosis factor family. Cell 199375 1169-1178.

9 Kawakami A, Eguchi K, Matsuoka N, Tsuboi M, Kawabe Y, Ishikawa $\mathrm{N}$ et al. Thyroid-stimulating hormone inhibits Fas antigen-mediated apoptosis of human thyrocytes in vitro. Endocrinology 1996137 3163-3169.

10 Stassi G, Todaro M, Richiusa P, Giordano P, Mattina A, Sbriglia MS et al. Expression of apoptosis inducing CD95 (Fas/Apo1) on human beta-cells (Abstract). Diabetologia 199539 (Suppl) A10.

11 Giordano C, Stassi, G, Todaro M, Richiusa P, De Maria M, Giordano $\mathrm{M}$ et al. Triggering of Fas (Fas/Apo1)-induced apoptosis in human pancreatic beta cells (Abstract). Diabetologia 199639 (Suppl 1) A10.

12 Yamada K, Takane-Gyotoku N, Yuan X, Ichikawa F, Inada C \& Nonaka K. Mouse islet lysis mediated by interleukin 1-induced Fas. Diabetologia $1996391306-1312$.

13 Rasmussen AK, Hartoft-Nielsen ML, Stenvang JP, Ravnsbaek J, Buschard U \& Feldt-Rasmussen U. Interleukin-1beta suppresses apoptosis in human thyroid cells. Journal of Endocrinological Investigation 199720 (Suppl 5) 159.

14 Blüher M, Krohn K, Wallaschofski H, Braverman LE \& Paschke R. Cytokine gene expression in autoimmune thyroiditis in $\mathrm{BB} / \mathrm{W}$ rats. Thyroid (In Press).

15 Rennie DP, McGregor AM, Keast D, Weetman AP, Ford SM, Dieguez $\mathrm{C}$ et al. The influence of methimazole on thyroglobulininduced autoimmune thyroiditis in the rat. Endocrinology 1982 $112326-330$

16 Maciejewski J, Selleri C, Anderson S \& Young NS. Fas antigen expression on CD34+ human bone marrow cells is induced by interferon gamma and TNF alpha potentiates cytokine-mediated hematopoietic suppression in vitro. Blood 199585 3183-3190. 
17 Weller M, Frei K, Groscurth P, Krammer PH, Yonekawa Y \& Fontana A. Anti-Fas/Apo-1 antibody-mediated apoptosis of cultured human glioma cells. Induction and modulation of sensitivity by cytokines. Journal of Clinical Investigation 199494 954-964.

18 Suarez-Pinzon W, Sorensen O, Bleackley RC, Elliott JF, Rajotte RV \& Rabinovich A. Beta-cell destruction in NOD mice correlates with Fas (CD 95) expression on beta-cells and proinflammatory cytokine expression in islets. Diabetes 199948 21-28.

19 Keane M, Ettenberg S, Lowrey G, Russell E \& Lipkowitz S. Fas expression and function in normal and malignant breast cancer cell lines. Cancer Research 199656 4791-4798.

20 Kubo K, Matsuzaki Y, Okazaki M, Kato A, Kobayashi N \& Okita K. The Fas system is not significantly involved in apoptosis in human hepatocellular carcinoma. Liver 199818 117-123.

21 Luo KX, Zhu YF, Zhang LX, He HT, Wang XS \& Zhang L. In situ investigation of Fas/FasL expression in chronic hepatitis $B$ infection and related liver diseases. Journal of Viral Hepatitis 19974 303-307.

22 Ito N, Tsujimoto Y \& Nagata S. Effect of bcl-2 on Fas antigenmediated cell death. Journal of Immunology $1993151621-$ 627.

23 Tamura M, Kimura H, Koji T, Tominaga T, Ashizawa K, Kiriyama $\mathrm{T}$ et al. Role of apoptosis of thyrocytes in a rat model of goitre. A possible involvement of the Fas system. Endocrinology 1998139 3646-3653.

24 French LE \& Tschopp J. Constitutive Fas ligand expression in several non-lymphoid mouse tissues: implications for immuneprotection and cell turnover. Behring Institute Mitteilungen 1996 97 156-160.

Received 31 March 1999

Accepted 20 July 1999 